\title{
Anger and perceived parenting: A study of a Japanese population
}

\author{
Toshinori Kitamura $^{1,2}$, Yukiko Ohashi ${ }^{1}$, Mikihiko Murakami ${ }^{3}$, Yoshitaka Goto ${ }^{3}$ \\ ${ }^{1}$ Kitamura Institute of Mental Health Tokyo, Tokyo, Japan \\ ${ }^{2}$ Department of Psychiatry, Graduate School of Medicine, Nagoya University, Nagoya, Japan \\ ${ }^{3}$ Kumamoto Paediatric Association, Kumamoto, Kumamoto, Japan
}

\section{Email address:}

kitamura@institute-of-mental-health.jp (T. Kitamura)

\section{To cite this article:}

Toshinori Kitamura, Yukiko Ohashi, Mikihiko Murakami, Yoshitaka Goto. Anger and Perceived Parenting: A Study of a Japanese Population. Psychology and Behavioral Sciences. Vol. 2, No. 6, 2013, pp. 217-222. doi: 10.11648/j.pbs.20130206.13

\begin{abstract}
To assess the effects of perceived rearing during childhood on adult trait anger and anger expression, we evaluated parents of young children attending paediatric clinics $(\mathrm{N}=1118)$. Participants rated their trait anger level and anger expression styles using the State-Trait Anger Expression Inventory and also rated the rearing patterns of their parents during childhood using the Parental Bonding Instrument. A structural equation model suggested that (1) Anger In and Anger Out were predicted by Trait Anger, while Anger Control was predicted by low Trait Anger; (2) Trait Anger was predicted by the affectionless control rearing style of participants' fathers during childhood, but not by their mothers' rearing styles; and (3) none of the anger expression scores were predicted directly by the perceived rearing of the participants' parents. Results did not differ between male and female participants. Adult trait anger may be explained by people's perception of their rearing during childhood.
\end{abstract}

Keywords: Trait Anger, Anger Expression, Perceived Rearing

\section{Introduction}

Anger has been studied considerably less frequently than other emotions such as anxiety, depression, happiness, and irritability. Behaviour and the human mind, however, cannot be adequately understood without an appreciation of the pivotal role played by anger. Studies have examined the relation of anger with hypertension and cardiac diseases [1-14], eating disorders [15-25], and personality disorders [26, pp 20-21; 27, pp 267-268], as well as many other psychiatric disorders.

Anger is both an internal experience and a mode of expression [13, 28, 29]. While feeling anger internally, people may express it outwardly, suppress it inwardly, or control it. Although anger expression is based on internal feelings of anger, the way it is expressed depends on a number of factors. Thus, individual differences in terms of liability to feel anger and express it still require investigation. One factor influencing feelings of anger and anger expression may be the way people were reared as children. For example children's anger is reported to be led by parents who are aggressive or who demonstrate high levels of trait anger [30,31]. Adult or adolescent anger and violence are associated with a history of childhood maltreatment [32-43]. In adolescents and young adults, borderline personality traits, including anger proneness, have been reported to be associated with childhood emotional abuse, even after controlling for the effects of physical abuse [44].

In contrast, perceived parenting during childhood has been studied only minimally in terms of its association with trait anger and anger expression. Parker [45] claimed that parental attitudes characterised by overprotection and low affection were associated with mood and anxiety disorders in adulthood, an association that has widely been recognised [46]. This parenting pattern has been termed affectionless control. This study aimed to test our hypothesis that poor parenting during childhood may be linked to trait anger and anger expression in adulthood.

\section{Methods}

\subsection{Participants ad Procedures}

As a part of a mental health survey of young children and parents in Japan, this questionnaire study was conducted 
with parents of young children aged 0 to 9 who attended one of 20 paediatrics clinics in Kumamoto Prefecture. Each participant was asked to fill in the questionnaire and return it to the researcher in a stamp-added envelope, and also to hand the questionnaire to his or her spouse, who was asked to participate in the survey.

Questionnaires were returned by the parents of 759 children (397 fathers and 721 mothers). Thus a total of $1118(397+721)$ questionnaires was used for further analyses. The mean (SD) age of the fathers was 35.2 (6.5) years and that of the mothers was 33.3 (5.5) years, with a significant $(p<.001)$ difference between them.

\subsection{Measurements}

\subsubsection{Trait Anger and Anger Expression}

The participants rated their own trait anger and anger expression styles using the State-Trait Anger Expression Inventory (STAXI) [13]. This is a self-report measure consisting of 44 items that form five scales-State Anger (10 items), Trait Anger (10 items), Anger In (eight items), Anger Out (eight items), and Anger Control (eight items). The STAXI was translated into Japanese [47]. To reduce the overall number of items in the questionnaire (which included other items not analysed in this report), we excluded all the State Anger items and reduced the number of Anger In, Anger Out, and Anger Control items to three each. For each of these scales, we selected the three items that had the highest factor loadings in an exploratory factor analysis of the STAXI in a Japanese population [47]. The possible scores ranged from 0 to 30 for Trait Anger and from 0 to 9 for Anger In, Anger Out, and Anger Control. Missing values of STAXI items were substituted with the mean of the item only when fewer than 16 items $(20 \%$ of the total number of items) were missing.

\subsubsection{Perceived Rearing}

Participants rated their parents' rearing attitudes during childhood using the Parental Bonding Instrument (PBI) [48]. This measure is used to retrospectively assess how individuals perceived their father's and mother's parenting (separately) before they were aged 16. Parker et al. [48] suggested that the parental contribution to a child's attachment security may be principally influenced by two variables: Care and Overprotection. The Care dimension (12 items rated on a 4-point scale, from 0 to 3 ) is defined by coldness, indifference, and neglect on one end, and affection, emotional warmth, empathy, and reciprocity on the other. This subscale includes items like "spoke to me with a warm and friendly voice", and "frequently smiled at me". The Overprotection dimension (13 items rated on a 4-point scale) ranges from parental control, overprotection, intrusion, and infantilization on the one hand, to parental allowance, independence, and the development of autonomy on the other. This subscale includes items like "invaded my privacy", and "tried to make me dependent on him". The PBI has been demonstrated to have acceptable validity [45]. A Japanese version of this scale has been previously developed [49]. Uji et al. [50] and Suzuki and Kitamura [51] demonstrated that the factor structure of the PBI in a Japanese population was virtually the same as that reported originally [45]. Missing values of PBI items were substituted with the mean of the item only when fewer than 20 items ( $20 \%$ of the total number of items) were missing.

\subsection{Statistics}

We calculated means, SDs, skewness, kurtosis, and internal consistencies (calculated as the Cronbach's alpha coefficient if the variable consisted of more than one item) for all the variables used in this study, as well as the correlation coefficients between them.

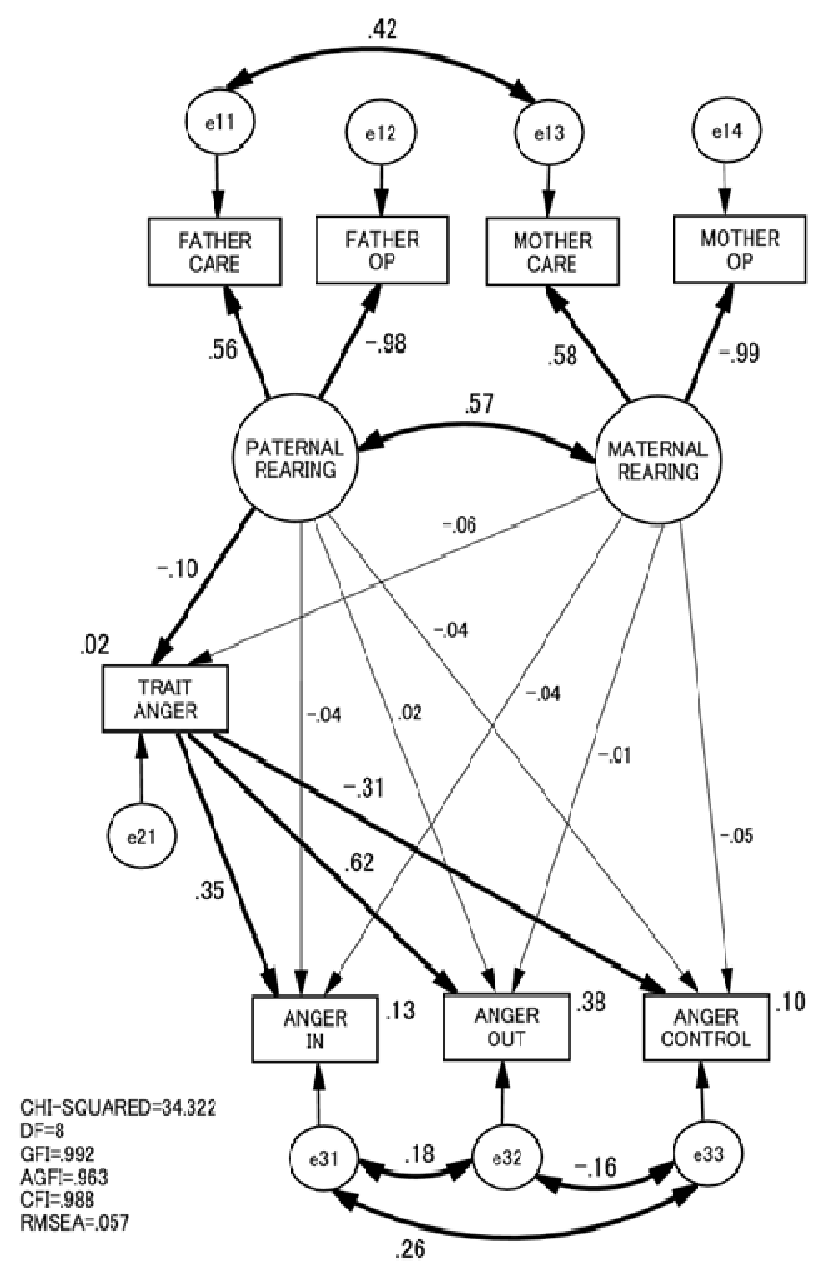

Figure 1. Path model with estimates. Estimates with $p>.05$ are in non-bold. Significant $(p<.05)$ estimates are in bold.

We then examined the relationships between perceived parenting styles and trait anger and anger expression. We used structural equation modelling (SEM) to create a path model (Fig. 1) in which we posited that (1) two latent variables, Paternal Rearing and Maternal Rearing, would be influenced by the two PBI scale scores; (2) Paternal and Maternal Rearing scores would influence the scores of all the STAXI subscales; and (3) Trait Anger scores would influence the scores of all three anger expression subscales. Covariances were added if the modification index 
suggested it, and such addition was recognised as being based on a theoretical background.

Table 1. Correlations, means, and SDs of all variables used in this study $(N=1118)$

\begin{tabular}{|c|c|c|c|c|c|c|c|c|c|c|}
\hline & 1 & 2 & 3 & 4 & 5 & 6 & 7 & 8 & 9 & 10 \\
\hline 1. Trait Anger & --- & & & & & & & & & \\
\hline 2. Anger-In & $.36^{* * *}$ & --- & & & & & & & & \\
\hline 3. Anger-Out & $.62 * * *$ & $.36 * * *$ & --- & & & & & & & \\
\hline 4. Anger Control & $-.30 * * *$ & $.13 * * *$ & $-.31 * * *$ & --- & & & & & & \\
\hline 5. Paternal Care & $-.09 * *$ & $-.17 * * *$ & -.04 & -.04 & --- & & & & & \\
\hline 6. Paternal OP & $.14 * * *$ & $.10^{* *}$ & $.07 *$ & .03 & $-.56^{* * *}$ & --- & & & & \\
\hline 7. Maternal Care & $-.10 * *$ & $-.11 * * *$ & $-.07 *$ & .05 & $-.47 * * *$ & $-.33^{* * *}$ & --- & & & \\
\hline 8. Maternal OP & $.12 * *$ & $.10^{* *}$ & $.08^{*}$ & .04 & $-.31 * * *$ & $.56 * * *$ & $-.57 * * *$ & --- & & \\
\hline 9. Age & $-.08 * *$ & -.04 & $-.09 * *$ & .05 & -.05 & .06 & -.04 & $.10^{* *}$ & --- & \\
\hline 10. Gender (male 1; female 2) & $-.11^{* * *}$ & -.00 & $-.08^{*}$ & $.17 * * *$ & -.03 & $.07 *$ & .02 & .06 & $.15^{* * *}$ & --- \\
\hline Mean & 14.8 & 4.2 & 3.9 & 5.1 & 23.0 & 11.7 & 27.0 & 11.2 & 34.1 & 1.3 \\
\hline SD & 5.1 & 1.9 & 1.8 & 1.6 & 7.2 & 6.4 & 6.4 & 6.8 & 5.4 & 0.5 \\
\hline Skewness & 0.2 & 0.0 & -.01 & -0.2 & -0.4 & 0.6 & -0.9 & 0.6 & 0.3 & --- \\
\hline Kurtosis & 0.6 & 0.1 & -0.1 & 0.6 & 0.1 & 0.2 & 0.9 & 0.3 & 0.1 & --- \\
\hline Cronbach's alpha & .859 & .695 & .659 & .643 & .913 & .859 & .913 & .884 & --- & --- \\
\hline
\end{tabular}

OP: Overprotection, ${ }^{*} \mathrm{p}<.05 ; * * \mathrm{p}<.01 ; * * * \mathrm{p}<.001$

The fit of the model with the data was examined in terms of chi-squared (CMIN), goodness-of-fit index (GFI), adjusted goodness-of-fit index (AGFI), comparative fit index (CFI), and root mean square error of approximation (RMSEA). According to conventional criteria, a good fit would be indicated by $\mathrm{CMIN} / \mathrm{df}<2$, GFI $>.95$, AGFI $>.90$, CFI $>.97$, and RMSEA $<0.05$, and an acceptable fit by $\mathrm{CMIN} / \mathrm{df}<3$, GFI $>.90$, AGFI $>.85$, CFI $>.95$, and RMSEA $<0.08$ [52].

Because we were interested in whether perceived parenting during childhood would affect trait anger and anger expression differently in male and female participants, we conducted multi-group SEM. Starting with a model without any constraints, a more constrained model was compared with a less constrained model. The null hypothesis was that the less constrained model was correct. If the chi-square difference between the two models did not reach a statistically significant level, we assumed that the more constrained model was correct.

\section{Result}

The psychometric properties of the variables used in this study are shown in Table 1. While Anger Out was correlated with Anger In, the former was inversely correlated with Anger Control but the latter was positively correlated with Anger Control. Trait Anger was correlated with Anger In and Anger Out but inversely correlated with Anger Control.

Trait Anger and Anger In were correlated with low parental Care and high parental Overprotection (affectionless control). A similar trend was found for Anger Out. Anger Control was not correlated with any of the parental style scores.

The original path model showed acceptable fit with the data. Thus CMIN/df $=4.29, \mathrm{GFI}=.992, \mathrm{AGFI}=.963, \mathrm{CFI}$ $=.988$, and RMSEA $=0.057$. Results showed that (1) Anger-In and Anger-Out were predicted by Trait Anger, while Anger Control was predicted by low Trait Anger; (2) Trait Anger was predicted by poor Paternal Rearing but not by Maternal Rearing; and (3) none of the anger expression scores were predicted directly by Paternal or Maternal Rearing scores

When we compared the results of male and female participants in the above model, we found that the construction of the measurement and structural models' weights as well as the structural model's covariances was correct. This suggested that male and female participants did not differ in the above model except in terms of error variances.

\section{Discussion}

The present study showed that while none of the anger expression styles were predicted by how participants had been reared by their parents, trait anger was predicted by their fathers' attitudes towards them during childhood. Maternal attitudes failed to predict trait anger or anger expression styles.

Anger was associated with affectionless control of fathers during childhood. Because it is possible that participant gender affected the influence of perceived paternal rearing on trait anger, we conducted a multi-group comparison between male and female participants. This revealed that the SEM model was almost the same between the two sexes. Hence the effects of paternal influence on trait anger did not 
show any gender difference. Men and women with high trait anger were more likely to share their fathers' attitudes, being less affective and more protective. Despite its importance [53], paternal involvement in childcare has been studied less than it should be. Our study suggests that children's responses (including trait anger) to parental affectionless control depend on the gender of the parent. For example, Kitamura et al. [54] studied a community population in a rural area in Japan and found that people with a history of recurrent or chronic depression were more likely to report that their mothers punched them while they were aged 16 or younger, but there was no association between paternal abuse and depression in adulthood.

Another notable aspect of the present findings is the lack of direct association between perceived parental rearing patterns and anger expression styles, although the zero-order correlation matrix showed a correlation between Anger In and both maternal and paternal affectionless control. People who were scored high in Trait Anger were more likely to suppress and express outwardly their feelings of anger but less likely to control these feelings. These effects may be mediated by Trait Anger as indicated by the SEM model.

Caution should be taken before making conclusions based on this study. Although we used a fairly large sample of non-clinical subjects, they were neither randomly selected nor representative of the Japanese population. The participation rate was particularly poor among fathers of children attending paediatric clinics. A second concern is that all information was derived from participants themselves, and our results are therefore subject to shared informant bias.

The association between the affectionless control parenting style of fathers during childhood and trait anger in adulthood may be mediated by third variables. Anger is a personality trait and thus may be explainable by personality. Personality may also be explained by early experiences such as perceived rearing [55-60]. Hence it is possible that the association between affectionless control and trait anger may be mediated by particular personality traits. This is an important research topic for future study. The fact that only a small portion of participants' Trait Anger was explainable by perceived rearing in this report suggests that further study is necessary to identify other possible determinants of trait anger.

The cultural background of this study should also be considered. Bear et al. [61] recently compared the guilt and anger feelings of American and Japanese fourth and fifth graders, and found that Japanese children were more likely to experience anger. Hence the results of the current study should be replicated with subjects of different cultural backgrounds.

Taking into consideration the drawbacks of the present study, this preliminary report suggests that perceived rearing by fathers (but not by mothers) is associated to some degree with adult trait anger and that it mediates the effects of perceived rearing on anger expression styles.

\section{Acknowledgement}

We thank the following paediatricians for their cooperation in collecting the data: Tsuneyoshi Egami, M.D., Hisako Fujikawa, M.D., Akio Furuse, M.D., Yoshiko Hattori, M.D., Yogo Haraguchi, M.D., Kaneshige Iribe, M.D., Tsunehiro Kuwahara, M.D., Toshinari Maeda, M.D., Hiroshi Mitsubuchi, M.D., Toru Miyazaki, M.D., Yuji Mizumoto, M.D., Ryozaburo Seguchi, M.D., Yasushi Shimada, M.D., Shigeto Sugino, M.D., Keiichi Taku, M.D., Tekehiko Ueno, M.D., Kyoko Uramoto, M.D., Ken Watanabe, M.D.

\section{References}

[1] F. Alexander, "Emotional factors in essential hypertension," Psychosomatic Medicine, vol. 1, pp. 175-179, 1939.

[2] M. E. Bleil, J. M. McCaffery, M. F. Muldoon, K. Sutton-Tyrrell, and S. B. Manuck, "Anger-related personality traits and carotid artery athelosclerosis in untreated hypertensive men," Psychosomatic Medicine, vol. 66, pp. 633-639, 2004.

[3] S. Booth-Kewley and H. S. Friedman, "Psychological predictors of heart disease: A quantitative review," Psychological Bulletin, vol. 101, pp. 343-362, 1987.

[4] T. M. Dembroski, J. M. MacDougall, R. B. Williams, T. L. Haney, and J. A. Blumenthal, "Components of type A, hostility, and anger-in: relationship to angiographic findings," Psychosomatic Medicine, vol. 47, pp. 219-233, 1985.

[5] E. L. Diamond, "The role of anger and hostility in essential hypertension and coronary heart disease," Psychological Bulletin, vol. 92, pp. 410-433, 1982.

[6] J. E. Dimsdale, C. Pierce, D, Schoenfeld, A, Brown, R. Zusman, and R. Graham, "Suppressed anger and blood pressure: the effects of race, sex, social class, obesity, and age," Psychosomatic Medicine, vol. 48, pp. 430-436, 1986.

[7] S. A. Everson, D. E. Goldberg, G. A. Kaplan, J. Julkunen, and J. T. Salonen, "Anger expression and incident hypertension," Psychosomatic Medicine, vol. 60, pp. 730-735, 1998.

[8] W. D. Gentry, A. P. Chesney, H. E. Gary, R. P. Hall, and E. Harburg, "Habitual anger-coping styles: I. effect on mean blood pressure and risk for essential hypertension," Psychosomatic Medicine, vol. 44, pp.195-202, 1982.

[9] E. Harburg, L. Gleiberman, M. Russell, and M. L. Cooper. "Anger-coping styles and blood pressure in black and white males," Psychosomatic Medicine, vol. 53, pp. 153-164, 1991.

[10] P. J. Mills and J. E. Dimsdale, "Anger suppression: its relationship to $\beta$-adrenergic receptor sensitivity and stress-induced changes in blood pressure," Psychological Medicine, vol. 23, pp. 673-678, 1993.

[11] A. W. Siegman, "Cardiovascular consequences of expressing and repressing anger," in Anger, hostility, and the heart, A. W. Siegman and T. W. Smith, Eds. Hillsdale, NJ: Lawrence Erlbaum, 1994, pp. 173-197 
[12] A. W. Siegman, S. T. Townsend, R. S. Blumenthal, J. D. Sorkin, and A. C. Civelek, "Dimensions of anger and CHD in men and women: self-ratings versus spouse ratings," Journal of Behavioral Medicine, vol. 21, pp.315-336, 1998.

[13] C. D. Spielberger, Manual for the State-Trait Anger Expression Inventory (STAXI). Odessa, FL: Psychological Assessment Resources, 1988.

[14] R. B. Williams and V. Williams, Anger kills. New York: Harper, 1994.

[15] S. Fassino, G. A. Daga, A. Piero, P. Leombruni, and G. G. Rovera, "Anger and personality in eating disorders," Journal of Psychosomatic Research, vol. 51, pp. 757-764, 2001.

[16] S. Fassino, G. A. Abbate Daga, A. Pierò, and G. G. Rovera, "Dropout from brief psychotherapy in anorexia nervosa," Psychotherapy and Psychosomatics, vol. 71, pp.200-206, 2002.

[17] M. Fava, S. M. Rappe, J. West, and D. B. Herzog, “Anger attacks in eating disorders," Psychiatry Research, vol. 28, pp. 205-212, 1995.

[18] A. Favaro and P. Santonastaso, "Different types of self-injurious behavior in bulimia nervosa," Comprehensive Psychiatry, vol. 40, pp. 57-60, 1999.

[19] J. Geller, S. J. Cockell, and E. M. Goldner, "Inhibited expression of negative emotions and interpersonal orientation in anorexia nervosa," Intenational Journal of Eating Disorder, vol. 28, pp.8-19, 2000.

[20] N. Horesh, G. Zalsman, and A. Apter, "Internalized anger, self-control, and mastery experience in inpatient anorexic adolescents," Journal of Psychosomatic Research, vol. 49, pp. 247-253, 2000

[21] M. Macht, "Characteristics of eating in anger, fear, sadness and joy," Appetite, vol. 33, pp. 129-139, 1999.

[22] R. J. Milligan and G. Waller, "Anger and bulimic psychopathology among nonclinical women," Intenational Journal of Eating Disorder, vol. 28, pp. 446-50, 2000.

[23] K. M. Thompson, S. A. Wonderlich, R. D. Crosby, and J. E. Mitchell, "The neglect link between eating disturbances and aggressive behavior in girls," Journal of the American Academy of Child and Adolescent Psychiatry, vol. 38, pp.1277-1284, 1999.

[24] J. Tiller, .U. Schmidt, and S. Ali, "Treasure J. Patterns of punitiveness in women with eating disorders" International Journal of Eating Disorder, vol. 17, pp. 365-371, 1995.

[25] S. L. Zaitsoff, J. Geller, and S. Srikameswaran, "Silencing the self and suppressed anger: Relationship to eating disorder symptoms in adolescent females, European Eating Disorder Review, vol. 10, pp. 51-60, 2002.

[26] J. F. Clarkin, F. E. Yeomans, and O. F. Kernberg, Psychotherapy for borderline personality: Focussing on object relations. Washington DC: American Psychiatric Publishing, 2006.

[27] O. F. Kernberg, Borderline conditions and pathological narcissism. Northvale, NJ: Jason Aronson, 1975.

[28] C. D. Spielberger, State-Trait Anger Expression Inventory: Professional manual. Odessa, FL: Psychological Assessment Resources, 1996.
[29] C. D. Spielberger, E. C. Recheisiser, and S. J. Sydeman, "Measuring the experience expression and control of anger" Issue of Comprehensive Paediatric Nursing, vol. 18, pp. 207-232, 1995.

[30] J. M. Jenkins, J. D. Shapka, and A. M. Sorenson, "Teenage mothers' anger over twelve years: partner conflict, partner transitions and children's anger," Journal of Child Psychology and Psychiatry, vol. 47, pp.775-782, 2006.

[31] S. Salzinger, R. S. Feldman, and M. Hammer, "The effects of physical abuse on children's social relationships," Child Development, vol. 64, pp.169-187, 1993.

[32] K. D. Browne and C. E. Hamilton, "Physical violence between young adults and their parents: associations with a history of child maltreatment," Journal of Family Violence, vol.13, pp.59-79, 1998.

[33] A. D. Cast, D. Schweingruber, and N. Berns, "Childhood physical punishment and problem solving in marriage," Journal of Interpersonal Violence, vol. 21, pp.244-261, 2006.

[34] C. L. Chapple, "Examining intergenerational violence: violent role modeling or weak parental control?," Violence and Victims, vol. 18, pp.143-162, 2003.

[35] C. L. Chapple, K. A. Tyler, and B. E. Bersani, "Child neglect and adolescent violence: examining the effects of self-control and peer rejection," Violence and Victims, vol.20, pp.39-53, 2005.

[36] K. A. Dodge, J. E. Lochman, J. D. Harnish, J E. Bates, and G. S. Pettit, "Reactive and proactive aggression in school children and psychiatrically impaired chronically assaultive youth, Journal of Abnormal Psychology, vol.106, pp. 37-51, 1997.

[37] J. Haapasalo and J. Moilanen, "Official and self-reported childhood abuse and adult crime of young offenders," Criminal Justice and Behavior, vol. 31, pp. 127-149, 2004.

[38] V. M. Herrera and L. A. McCloskey, "Sexual abuse, family violence, and female delinquency: findings from longitudinal study," Violence and Victims, vol.18, pp. 319-334, 2003.

[39] D. J. Higgins and M. P. McCabe, "Maltreatment and family dysfunction in childhood and the subsequent adjustment of children and adults," Journal of Family Violence, vol. 18, pp. 107-120, 2003.

[40] M. Lutenbacher, "Relationships between psychosocial factors and abusive parenting attitudes in low-income single mothers" Nursing Research, vol. 51, pp. 158-167, 2002.

[41] J. A. Luterek, G, Harb, R. G. Heimberg, and B, P, Marx, "Interpersonal rejection sensitivity in childhood sexual abuse survivors: mediator of depressive symptoms and anger suppression," Journal of Interpersonal Violence, vol. 19, 90-107, 2004

[42] S. Roseman and B. Rogers, "Childhood adversity and adult personality," Australian and New Zealand Journal of Psychiatry, vol. 40, pp. 482-490, 2006.

[43] K. A. Tyler and K. A. Johnson, "A longitudinal study of the effects of early abuse on later victimization among high-risk adolescents," Violence and Victims, vol. 21, pp. 287-306, 2006. 
[44] H. Igarashi, C. Hasui, and M. Uji, "Shono M, Nagata T, Kitamura T. Effects of child abuse history on borderline personality traits, negative life events, and depression: A study among a university student population in Japan," Psychiatry Research, vol. 180, pp.120-152, 2010.

[45] G. Parker, Parental Overprotection: A Risk Factor in Psychosocial Development. Grune \& Stratton, New York: 1983.

[46] G. Parker, "The parental bonding instrument: A decade of research," Social Psychiatry and Psychiatric Epidemiology, vol.25, pp. 281-282, 1990.

[47] T. Suzuki and Y. Haruki, "Ikari to junkankikei shikkan no kanrensei no kentou :The relationship between anger and circulatory disease," Japanese Journal of Health Psychology, vol.7; pp. 1-13, 1994. (in Japanese)

[48] G. Parker, H. Tupling, and L. B. Brown, "A parental bonding instrument," British Journal of Medical Psychology, vol. 52, pp. $1-10,1979$.

[49] T. Kitamura and T. Suzuki. "A validation study of the Parental Bonding Instrument in a Japanese population," Japanese Journal of Psychiatry and Neurology, vol. 47, pp.29-36, 1993.

[50] M. Uji, N. Tanaka, M. Shono and T. Kitamura, "Factorial structure of the Parental Bonding Instrument (PBI) in Japan: a study of cultural, developmental, generational, and sexual influences," Child Psychiatry and Human Development; vol. 37 , pp. 115-132, 2006

[51] H. Suzuki and T. Kitamura, "The parental bonding instrument: A four-factor structure model in a Japanese college sample," Open Family Studies Journal, vol. 4, pp. 89-94, 2011.

[52] K. Schermelleh-Engel1, H. Moosbrugger, and H. Müller, "Evaluating the fit of structural equation models: tests of significance and descriptive goodness-of-fit measures," Method of Psychological Research Online, vol. 8, pp. 23-74, 2003.

[53] N. J. Cabrera, C. S. Tamis-LeMonda, R. H. Bradley, S.
Hofferth, and M. E. Lamb, "Fatherhood in the twenty-first century," Child Development, vol. 71, pp. 127-136,2000.

[54] T. Kitamura, N. Kijima, W. Aihara, A. Tomoda, R. Fukuda, and M. Yamamoto. "Depression and early experiences among young Japanese women: multiple facets of experiences and subcategories of depression," Archives of Women's Mental Health, vol. 1, pp. 27-37, 1998.

[55] S. Benhaminsen, J. Jorgensen, L. Kragh-Hansen, and L. L. Pedersen, "Memories of parental rearing practices and personality features," Acta Psychiatrica Scandinavica, vol. 69, pp. 426-434, 1984.

[56] T. Kitamura and Y. Kishida, "Early experiences and development of personality: A study of the Temperament and Character Inventory in 4000 university students in Japan," in Trends in lifestyle and health research, L. V. Kingler, Eds. Hauppauge: Nova Science Publishers, 2005, pp. 1-20.

[57] T. Kitamura, A. Tomoda, N. Kijima, S. Sakamoto, E. Tanaka, and N. Iwata, "Correlates of retrospective early life experience with personality in young Japanese women," Psychological Reports, vol. 91, pp. 263-274, 2002.

[58] Y. Ono, K. Yoshimura, H. Mizushima, H. Manki, G. Yagi, S. Kanba, J. Nathan, and M. Asai, "Environmental and possible genetic contributions to character dimensions of personality," Psychological Reports, vol. 84, pp. 689-696, 1999.

[59] I. M. Reti, J. F. Samuels, W. W. Eaton, O. J. Bienvenu III, P. T. Costa Jr., and G. Nestadt, "Influence of parenting on normal personality traits," Psychiatry Research, vol. 111, pp. 55-64, 2002.

[60] V. V. Ruchkin, M. Eisemann, B. Hägglöf, and C. R. Cloninger, "Interrelations between temperament, character, and parental rearing in male delinquent adolescents in Northern Russia," Comprehen Psychiatry, vol. 39, pp. 225-230, 1998.

[61] G. G. Bear, X. Uribe-Zarain, M. A. Manning, and K. Shiomi, "Shame, guilt, blaming, and anger: differences between children in Japan and the US," Motivation and Emotion, vol.33, pp. 229-238, 2009. 